\title{
Comparison of Bis NEG-D and API 20E for the Identification of Gram-negative Bacilli in the Laboratory of the University Hospital of Befelatanana Antananarivo Madagascar
}

\author{
Zafindrasoa Domoina Rakotovao-Ravahatra, Lalaina Rahajamanana, Lalaina Rakotondraoelina, \\ Laurent Raskine, Saïda Rasoanandrasana, Christian Rafalimanana, Rivo Rakotomalala, \\ Arinomenjanahary Malalanandrianina Rakotoarisoa, Lalatiana Valisoa Andriambelo, \\ Hoby Tantelinirimiarana, Jocia Fenomanana, Irène Rakotoniaina, Zakasoa Ravaoarisaina, \\ Ainamalala Catherine Razafindrakoto, Tsiriniaina Ramavoson, Eddy Ramaminiaina, \\ Heritiana Randrianary, Andry Tiana Razafinikasa, Jean Emile Ravelomandranto, \\ and Andriamiadana Luc Rakotovao
}

\section{ABSTRACT}

In medical analysis laboratories, techniques for identifying bacteria are currently becoming more and more numerous. The objective of this study is to compare the 2 bacterial identification systems Bis NEG-D and Api $20 \mathrm{E}$ for the identification of gram-negative bacilli. This is a qualitative evaluation of the Bis NEG-D compared to the gold standard Api 20E. During the study period, 32 Gram-negative bacilli isolates were identified simultaneously using Api 20E and Bis NEG-D. The samples are represented by $12(37.5 \%)$ blood samples for blood culture, $12(37.5 \%)$ urine samples for cytobacteriological examination of the urine, $06(18.8 \%)$ pus samples for bacteriological examination of pus, a sample of the cerebrospinal fluid (3.1\%) and a vaginal sample (3.1\%).The bacteria identified were represented by Enterobacter spp, Escherichia col,i Klebsiella pneumonia, Shigella spp, Salmonella typhi, Acinetobacter baumannii, Pseudomonas spp, Proteus mirabilis, Raoultella ornithinolytica and Bukholderia cepacia. This study showed a concordance of $90.6 \%(29 / 32)$ and a discordance of $9.4 \%(3 / 32)$ between the results of Api $20 \mathrm{E}$ and Bis NEG-D. Concerning the probability scores, they vary between $95 \%$ to $100 \%$ for Api $20 \mathrm{E}$ and between $79.3 \%$ to $100 \%$ for Bis NEG-D. This study also compared the pros and cons of using Api $20 \mathrm{E}$ and Bis NEG-D. The Bis-NEG-D is valid and can be used by medical analysis laboratories like the Api 20E, especially if these laboratories do not need to perform a lot of bacterial identification tests.

Keywords: Bacteria, bacterial identification system, qualitative evaluation.
Published Online: October 22, 2020

ISSN: $2684-5199$

DOI: $10.24018 /$ ejbio.2021.2.5.286

Z. D. Rakotovao-Ravahatra*

(e-mail: ravahatradomoina@yahoo.fr)

L. Rahajamanana

(e-mail: v_lalaina@yahoo.fr)

L. Rakotondraoelina

(e-mail: lalainaraoelina@gmail.com)

L. Raskine

(e-mail:

laurent.raskine@fondation-merieux.org)

S. Rasoanandrasana

E-mail: rssaida@yahoo.fr

C. Rafalimanana

(e-mail: rafalimanana_christian@yahoo.com)

R. Rakotomalala

(e-mail: solorivo@yahoo.fr)

A. M. Rakotoarisoa

(e-mail: arimalala11@gmail.com)

L. V. Andriambelo

(e-mail: lalatiana.valisoa@gmail.com)

H. Tantelinirimiarana

(e-mail : htantel@yahoo.fr)

Jocia Fenomanana

(e-mail : jfenomanana@yahoo.fr)

I. Rakotoniaina

(e-mail : irenerakotoniaina2@yahoo.com)

Z. Ravaoarisaina

(e-mail : zakasoa.ravaoarisaina@yahoo.com)

A. C. Razafindrakoto

(e-mail : titarazafy@gmail.com)

T. Ramavoson

(e-mail : rtsirynyaina@gmail.com)

E. Ramaminiaina

(e-mail : eddy.ramaminiaina@yahoo.fr)

H. Randrianary

(e-mail: rheritiana200@yahoo.fr

Andry Tiana Razafinikasa

(e-mail : yaz_thune@yahoo.fr)

Jean Emile Ravelomandranto

E-mail: ravelomandranto@yahoo.fr)

Andriamiadana Luc Rakotovao

(e-mail: lucdina007@yahoo.fr)

All authors are with Medical Biology Department of the Faculty of Medicine,

University of Antananarivo, Madagascar.

*Corresponding Author 


\section{INTRODUCTION}

Bacterial infections account for a large proportion of people admitted to hospitals every year as well as some acquired by patients already in medical care [1]. These can be caused by the ingestion of contaminated food or the exposure to non-sterile environments through wounds where opportunistic pathogenic bacteria are present. The symptoms and treatment vary and although some clues can be obtained from the patient's symptoms, the causative agent needs to be determined in order for a complete understanding of the nature of infection, its origin, and the appropriate treatment. It is therefore of immense importance to characterize and identify these bacteria. The prognosis of bacterial infections depends not only on the antibiotics used and the sensitivity of the germs to these antibiotics [2]. The role of microbiology laboratories is to correctly identify bacteria and correctly perform the antibiogram in order to ensure proper management of the patient's infectious disease. Microbiology has been largely developed thanks to the discovery and optimization of bacterial identification systems. In recent years matrix assisted laser desorption ionization-time of flight mass spectrometry (MALDI-TOF MS) has emerged as a potential tool for microbial identification and diagnosis. During the MALDI-TOF MS process, microbes are identified using either intact cells or cell extracts [3].

However, in developing countries like Madagascar, manual bacterial identification systems are still used. The majority of bacteriology laboratories in Madagascar use the Api 20E bacterial identification system. However, the use of this kit has some drawbacks. Thus, it was decided to use other bacterial identification systems offered by the suppliers. This is the Bis NEG-D. Before using the Bis NEG-D, it must be compared with the Api $20 \mathrm{E}$. Thus, the objective of this study is to compare the 2 bacterial identification systems Bis NEGD and Api 20E for the identification of gram-negative bacilli.

\section{MATERIALS AND METHODS}

\section{A. Type and period of study}

This is an evaluative study by comparing the two bacterial identification systems Bis NEG-D and Api 20E over a period of 3 months from January 2021 to March 2021 in the laboratory of the University Hospital of Joseph Raseta Befelatanana.

\section{B. Procedures}

During the study period, 32 bacterial isolates were identified simultaneously with Bis NEG-D and Api 20E. BisNEG-D is a new bacterial identification system provided by Cypress Diagnostics and should be evaluated before use by comparing it with Api 20E. Indeed, since the opening of the bacteriology laboratory of the University Hospital of Joseph Raseta Befelatanana, the Api brand bacterial identification systems supplied by Biomérieux have been the only ones to be used in the laboratory. Thus, Api 20E represents the gold standard test in this study. It is a standardized identification system for Enterobacteriaceae and other non-fastidious, Gram-negative rods which uses 20 miniaturized biochemical tests and a database. The API 20E strip consists of 20 microtubes containing dehydrated substrates. These tests are inoculated with a bacterial suspension that reconstitutes the media. During incubation, metabolism produces color changes that are either spontaneous or revealed by the addition of reagents. The reactions are read according to the Reading Table and the identification is obtained by referring to the Analytical Profile Index or using the identification software. Each kit of API 20E contains 25 tests and we used 2 kits to identify the 32 bacterial isolates [4].

Regarding Bis NEG-D kit, it is a standardized identification panel for common Gram negative bacteria, consisting of 24 miniaturized biochemical tests and database. Each kit contains 16 tests and we used 2 kits to identify the 32 bacterial isolates. The Bis NEG-D is an identification system for 115 Gram negative bacteria. The Bis NEG- D system uses miniaturized biochemical methods to identify bacteria. The system gives accurate and reliable results within 24 hours. The panels are comprehensive and require only a very limited amount of consumables. This makes the system efficient, easy to use and lowers costs for the user. In addition, Cypress diagnostics provides clear and easy to use protocols. Downloadable software is available free of charge to all users from the Cypress diagnostics website. The software offers the identification of microorganisms with additional information on the reliability of the result obtained. The reliability of the result can be increased by additional tests [5].

\section{Study parameters}

Study parameters were represented by type of sample, bacteriological results on Bis NEG-D, bacteriological results on Api 20E, the probability score, concordance and discordance of the results, advantages and disadvantages of using Api 20E and.

\section{Ethical considerations}

This study was authorized by the director of establishment of the University Hospital of Befelatanana and the Department Head of the laboratory before its implementation. This study respected the notion of anonymity and confidentiality. Otherwise, this study was carried out with the technical and financial support of the company Médical International of Madagascar and the Mérieux Foundation.

\section{RESUlts}

\section{A. Types of Samples}

During the study period, 32 Gram-negative bacilli isolates were identified simultaneously using Api 20E and Bis NEGD. The samples are represented by $12(37.5 \%)$ blood samples for blood culture, $12(37.5 \%)$ urine samples for cytobacteriological examination of the urine, 06 (18.8\%) pus samples for bacteriological examination of pus, a sample of the cerebrospinal fluid $(3.1 \%)$ and a vaginal sample $(3.1 \%)$ (Fig. 1) 


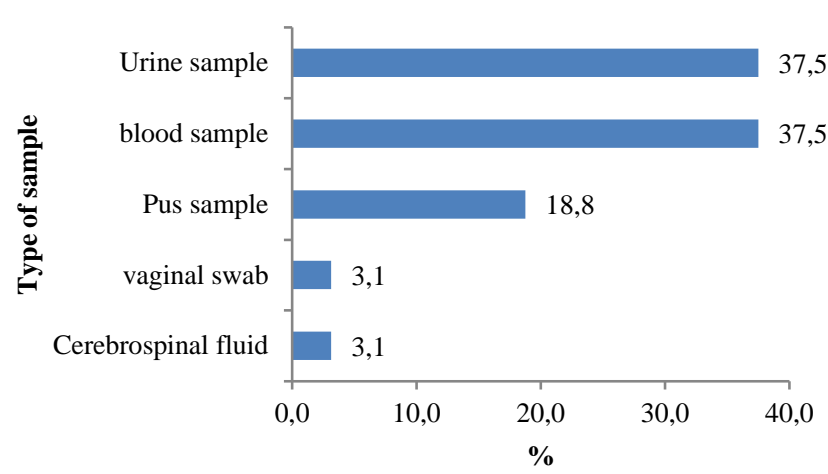

Fig.1. Types of samples for bacteriological examination.

\section{B. Concordance and Discordance of Results}

The bacteria identified were represented by Enterobacter cloace, Enterobacter aerogenes, Escherichia col,i Klebsiella pneumonia, Shigella spp, Salmonella typhi, Acinetobacter baumannii, Pseudomonas aeruginosa, Pseudomonas luteola, Proteus mirabilis, Raoultella ornithinolytica and Bukholderia cepacia. Among the 32 bacterial identification results performed simultaneously using Api $20 \mathrm{E}$ and Bis NEG-D, 3/32 results were discordant showing a concordance of $90.6 \%(29 / 32)$ and a discordance of $9.4 \%$ (3/32) between the results of Api 20E and Bis NEG-D (Table I).

TABLE I: CONCORDANCE AND DISCORDANCE OF RESULTS

\begin{tabular}{|c|c|c|c|}
\hline $\mathrm{n}^{\circ}$ & Bis NEG-D results & Api 20E results & Results \\
\hline 1 & Enterobacter cloace & Enterobacter cloace & Concordance \\
\hline 2 & Escherichia coli & Escherichia coli & Concordance \\
\hline 3 & Escherichia coli & Escherichia coli & Concordance \\
\hline 4 & Escherichia coli & Escherichia coli & Concordance \\
\hline 5 & Enterobacter cloace & Enterobacter cloace & Concordance \\
\hline 6 & Klebsiella pneumoniae & Klebsiella pneumoniae & Concordance \\
\hline 7 & Escherichia coli & Escherichia coli & Concordance \\
\hline 8 & Klebsiella pneumoniae & Klebsiella pneumoniae & Concordance \\
\hline 9 & Enterobacter cloace & Enterobacter cloace & Concordance \\
\hline 10 & Shigella spp & Salmonella typhi & Discordance \\
\hline 11 & Enterobacter aerogenes & Enterobacter aerogenes & Concordance \\
\hline 12 & Escherichia coli & Escherichia coli & Concordance \\
\hline 13 & Enterobacter cloace & Enterobacter cloace & Concordance \\
\hline 14 & Klebsiella pneumoniae & Klebsiella pneumoniae & Concordance \\
\hline 15 & Escherichia coli & Escherichia coli & Concordance \\
\hline 16 & Proteus mirabilis & Proteus mirabilis & Concordance \\
\hline 17 & Enterobacter cloace & Enterobacter cloace & Concordance \\
\hline 18 & Acinetobacter baumannii & $\begin{array}{c}\text { Acinetobacter } \\
\text { baumannii }\end{array}$ & Concordance \\
\hline 19 & Klebsiella pneumoniae & Klebsiella pneumoniae & Concordance \\
\hline 20 & Escherichia coli & Escherichia coli & Concordance \\
\hline 21 & Klebsiella pneumoniae & Klebsiella pneumoniae & Concordance \\
\hline 22 & Escherichia coli & Escherichia coli & Concordance \\
\hline 23 & Klebsiella pneumoniae & Klebsiella pneumoniae & Concordance \\
\hline 24 & Escherichia coli & Escherichia coli & Concordance \\
\hline 25 & Escherichia coli & Escherichia coli & Concordance \\
\hline 26 & Pseudomonas aeruginosa & Pseudomonas luteola & Discordance \\
\hline 27 & Enterobacter cloace & Klebsiella pneumoniae & Discordance \\
\hline 28 & Klebsiella pneumoniae & Klebsiella pneumoniae & Concordance \\
\hline 29 & Escherichia coli & Escherichia coli & Concordance \\
\hline 30 & Raoultella ornithinolytica & $\begin{array}{c}\text { Raoultella } \\
\text { ornithinolytica }\end{array}$ & Concordance \\
\hline 31 & Escherichia coli & Escherichia coli & Concordance \\
\hline 32 & Bukholderia cepacia & Bukholderia cepacia & Concordance \\
\hline
\end{tabular}

\section{Probability Scores}

Concerning the probability scores, they vary between $95 \%$ to $100 \%$ for Api $20 \mathrm{E}$ and between $79.3 \%$ to $100 \%$ for Bis NEG-D (Fig. 2).

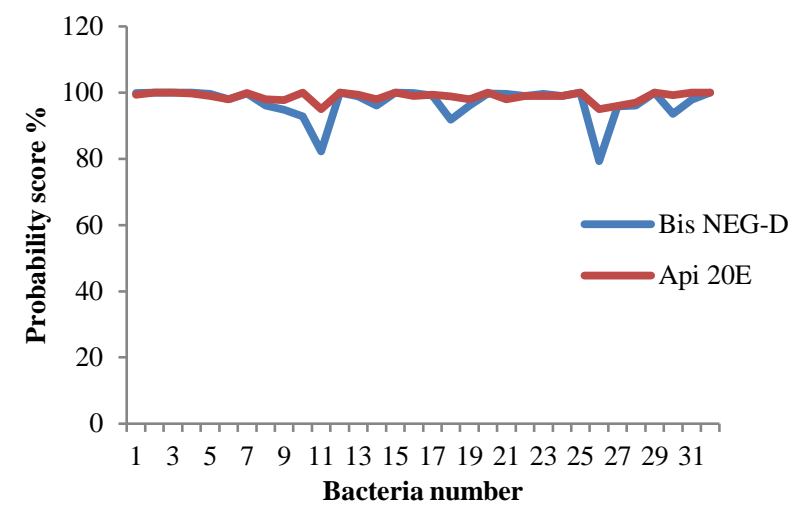

Fig. 2. Probability scores.

\section{Advantages and Disadvantages of Using Api $20 E$ and Bis NEG-D}

The advantages and disadvantages of using Api 20E and Bis NEG-D are detailed in Table II.

TABLE II: ADVANTAGES AND DISADVANTAGES OF USING API 20E AND BIS NEG-D

\begin{tabular}{ccc}
\hline & Advantages & Disadvantages \\
\hline Bis NEG-D & $\begin{array}{c}\text { The price is cheaper in the trade } \\
\text { Identifies of all Gram-negative } \\
\text { bacilli }\end{array}$ & $\begin{array}{c}\text { Need for several additional } \\
\text { tests } \\
\text { somes than } 80 \%\end{array}$ \\
\hline & $\begin{array}{c}\text { No need for additional tests } \\
\text { probability score greater than } \\
90 \%\end{array}$ & $\begin{array}{c}\text { short expiration date } \\
\text { thice is more expensive } \\
\text { in the trade }\end{array}$ \\
& & $\begin{array}{c}\text { Cannot identifies all Gram- } \\
\text { negative bacilli }\end{array}$ \\
\hline
\end{tabular}

\section{DISCUSSION}

Api 20E and Bis NEG-D systems are both bacterial identification systems. The identification process consists of recognizing an unknown bacterium by defining its membership in a species. It is based on the choice of a set of biochemical tests carried out by specific software. This set constitutes an identification kit. Depending on the response profile observed, a probability of belonging to each species is calculated. We retain the most probable species. A probability score between 60 and $100 \%$ means that the confidence level is high and therefore the identification is reliable. For a score $<60 \%$ the level of confidence is low, the software then proposing between two and four identifications [6-9]. Looking at all the probability scores for Api 20E and Bis NEG-D, they were all above $60 \%$. So, these 2 tests are reliable. However, if we detail the results, the probability scores of the 2 tests were all greater than $90 \%$ except for 2 bacteria identified by Bis NEG-D (82.2\% for Enterobacter aerogenes and $79.3 \%$ for Pseudomonas aeruginosa). Thus, we can conclude that the Bis NEG-D can make identification errors and Api 20E remains the gold standard. Moreover, Bis NEG-D identified Pseudomonas aeruginosa for the score of 79.3\% instead of Pseudomonas luteola identified by Api 20 E with a score of $95 \%$. Similarly, 2 other bacteria identified were also different for the 2 tests: Shigella spp for Bis NEGD (probability score of 92.8\%) against Salmonella typhi for Api 20E (probability score of 100\%) and Enterobacter cloacae for Bis NEG-D (probability score of 95.8\%) against 
Klebsiella pneumoniae for Api 20E (probability score of $96 \%$ ). Taking into account these 3 discordant results, there were $90.6 \%$ (29/32) concordant and 9.3\% (3/32) discordant results between bacterial identification of Api 20E and Bis NEG-D. In addition, all the probability scores of the Api $20 \mathrm{E}$ are greater than or equal to those of the Bis NEG-D for each germ identified. Thus, Api 20E remains the best bacterial identification system that should be used in bacteriology laboratories and represents the gold standard in this study.

Nevertheless, there are some disadvantages of using the Api 20E. First, the expiry date of the kits does not exceed one year when they arrive at the laboratory. Second, the kit can only identify Enterobacteriaceae as well as other nonfastidious, Gram-negative bacilli. We must use another kit called Api $20 \mathrm{NE}$ if we want to identify other Gram-negative bacilli. Third, Third, Api 20E costs more expensive than Bis NEG-D [4].

On the other hand, the use of Bis NEG-D has many advantages. First, the kit has an expiration date of two to three years when it arrives at the laboratory. Secondly, the kit can identify all Gram-negative bacilli without exception. Third, the kit costs less than the API kits [5].

And if we compare the discordant results between Api 20E and Bis NEG-D, there are similarities between the identified germs. First, the gender diagnosis was the same for the 2 kits in the identification of the Pseudomonas genus. The discordance concerned the species. Thus, the treatment of the patient does not change because all bacteria of the genus Pseudomonas are treated in the same way. The second discordance concerns 2 bacteria which belong to the same group called KES (Klebsiella-Enterobacter-Serratia) group. These are Enterobacter and Klebsiella. The treatment is also the same for these 2 germs. The third discrepancy concerned 2 germs which are both responsible for digestive disorders. These are Shigella and Salmonella. Here, the germ was identified from a blood culture sample. Thus, it is certain that it is Salmonella (identified by Api 20E) instead of Shigella (identified by Bis NEG-D) because the identification of Shigella in the blood culture is very rare [10]. Its identification is often done during the stool culture. Thus, among the 3 discordant results observed between Api 20E and Bis NEG-D, only one discordant result should be taken into account because the other 2 have no particular consequence on the therapeutic management of the patient. Moreover, the treatment will be undertaken based on the results of the antibiogram for all the germs identified.

Discordant results between Api 20E and Bis NEG-D may be due to handling errors, improper mixing of the inoculum or an error in reading the results by the technician. Thus, when using the Bis NEG-D test for the first time, the manipulation must be carried out by the technician in the presence of the medical biologist. Likewise, the results must be read by at least 3 people to avoid possible errors.

Based on all these results, Bis NEG-D is valid and could still be used in bacteriology laboratories in the absence of Api $20 \mathrm{E}$ because only one discordant result was taken into account since the other 2 did not no impact on patient care. Moreover, the good handling of the kit and the good respect of the technical procedures will make it possible to avoid identification errors and lead to the best probability score $(100 \%)$.
The results of this study allow us to make some recommendations. Large city laboratories that receive a lot of bacteriological analyzes should continue to use the Api $20 \mathrm{E}$ bacterial identification system as they can purchase it annually and the rapid expiry of this test is not a problem for them as well as the cost of the test. They can also use other Api tests such as Api 20NE for the identification of other Gram-negative bacilli. On the other hand, it is preferable that the small laboratories which do not do a lot of bacteriological analyze use the Bis NEG-D because its expiry date is long, and its price is cheaper on the market. Likewise, the small laboratory does not need to buy other bacterial identification systems for the identification of other Gram-negative bacilli because the Bis NEG-D is sufficient to identify them all.

In brief, the proper observance of standard operating procedures for each type of bacterial identification system should be carried out for performs a good bacterial identification in order to obtain the best probability score which is $100 \%$.

\section{CONCLUSIONS}

Api 20E remains the best identification bacterial system. However, Bis-NEG-D is valid and can be used by medical analysis laboratories, especially if these laboratories do not need to perform a lot of bacterial identification tests. The proper observance of standard operating procedures for each type of bacterial identification system should be carried out for performs a good bacterial identification in order to obtain the best probability score which is $100 \%$.

\section{ACKNOWLEDGEMENTS}

We would like to thank all the staff of the laboratory of University Hospital of Befelatanana and all the laboratory technicians. Similarly, we would like to express our gratitude to the director of establishment for authorizing us to carry out this study. And we warmly thank the International Medical Society of Madagascar and the Mérieux Foundation for the technical and financial support during the realization of this study.

\section{COMPETING INTERESTS}

Authors have declared that no competing interests exist.

\section{REFERENCES}

[1] D.K. Kakupa, P.K. Muenze, B. Byl, and M.D. Wilmet, "Study of the prevalence of nosocomial infections and associated factors in the two university hospitals of Lubumbashi, Democratic Republic of Congo", Pan Afr. Med.J., 24, pp. 275,2016.

[2] A. F. Jehl, A. Chabaud, and Grillon, "L'antibiogramme : diamètres ou CMI? ", J. Anti-infect., 17(4), pp. 125-139, 2015.

[3] N. Singhal, M. Kumar, P.K. Kanaujia, and J.S. Virdi, "MALDI-TOF mass spectrometry: an emerging technology for microbial identification and diagnosis", Front. Microbiol. 6, pp. 791, 2015.

[4] Api 20E instructions available online at http://biomanufacturing.org

[5] Bis NEG-D instructions available online at http://diagnostics.be

[6] J.H. Chen, P.L. Ho, G.S. Kwan, K.K. She, G.K. Siu, V.C. Cheng, et al, "Direct bacterial identification in positive blood cultures by use of two commercial matrix-assisted laser desorption ionization-time of flight mass spectrometry systems", J. Clin. Microbiol., 51, pp. 1733-1739, 2013. 
[7] J.Y. Moon, S.J. Kim, M.H. Moon, B.B. Chung, and M.H. Choi, "Differential

estimation of isomeric 2- and 4-methoxylated estrogens in serum by matrix-assisted laser desorption ionization-tandem mass spectrometry. Analytical sciences", JSAC., 29, pp. 345-351,2013.

[8] R. Patel, "Matrix-assisted laser desorption ionization-time of flight mass spectrometry in clinical microbiology. Clinical infectious diseases", IDSA., 57, pp. 564-572, 2013.

[9] L.F. Westblade, R. Jennemann, J.A. Branda, M. Bythrow, M.J. Ferraro, O.B. Garner, et al, "Multicenter study evaluating the Vitek MS system for identification of medically important yeasts", J. Clin. Microbiol., 51, pp. 2267-2272, 2013.

[10] C. Okalla Ebongueab, J.P. Nda Mefo'oab, E. Ngouadjeu Donghoab, E.C. Eboumbou Moukokobc, D. Adiogob, G. Beyiha, "Bacteriological profile and antimicrobial susceptibility of blood culture isolates (20062011) in Douala, Cameroon", REMIM., 2, pp. 27-39, 2014. 